\title{
Um estudo sobre compreensões acerca de complexidade em teses e dissertações brasileiras de educação ambiental que se relacionam com a educação em ciências
}

\author{
A study on comprehension about complexity in Brazilian environmental education \\ theses and dissertations that relate to science education
}
Un estudio sobre la comprensión de la complejidad en las tesis y disertaciones de educación ambiental brasileñas relacionadas con la enseñanza de las ciencias

\author{
Brenda Braga Pereira ${ }^{1}$ \\ Luciano Fernandes Silva ${ }^{2}$ \\ Janaína Roberta dos Santos ${ }^{3}$
}

\begin{abstract}
Resumo
Há um número expressivo e qualificado de trabalhos acadêmicos que tratam das complexidades relacionadas com temas ambientais, a partir de discussões que envolvem as áreas da educação ambiental e da educação em ciências. Nesse contexto, este trabalho tem por objetivo identificar e analisar compreensões acerca das complexidades em teses e dissertações da área de educação ambiental que se relacionam com a área da educação em ciências. Do ponto de vista metodológico, este é um trabalho que se articula com pesquisas denominadas de estado da arte. Para a construção do corpus documental utilizamos o banco de teses e dissertações do EArte (Estado da Arte em Educação Ambiental). Selecionamos vinte teses e dissertações para compor o corpus documental dessa investigação. Para a análise desse material, utilizamos o procedimento da Análise de Conteúdo. Construímos quatro categorias: Pensamento Complexo, Sistemas Complexos, Complexificação e Complexidades e Práticas Pedagógicas. Podemos apontar que a ideia de complexidade é frequentemente sustentada nestes trabalhos, a partir das considerações de Enrique Leff, Edgar Morin e Ilya Prigogine. Todavia, as considerações teóricas de Morin tendem a predominar, indicando uma perspectiva de discutir a complexidade mais pela via da complexificação da realidade e do pensamento do que pela consideração da complexidade inerente aos fenômenos naturais e sociais.
\end{abstract}

Palavras-chave: Educação Ambiental. Educação em Ciências. Complexidades. Processo Educativo.

\begin{abstract}
There is an expressive and qualified number of academic theses and dissertations that refers to the complexities in the discussions on environmental issues. Part of these theses and dissertations articulate the fields of environmental education and scientific education. This paper presents the results of an investigation focused on the understandings about the complexities related to the ideas that involve environmental education and science education. The EArte's database (Estado da Arte em Educação Ambiental) was used for the elaboration of the documentary corpus. Twenty theses and dissertations were selected to compose the documentary corpus of this investigation. The content analysis procedure was used for the analysis of theses and dissertations. Four categories were elaborated: Complex Thinking, Complex Systems, Complexification and Complexities and Pedagogical Practices. The idea of complexity is often supported in these thesis and dissertations, from the considerations of Enrique Leff, Edgar Morin and Ilya Prigogine. However, Morin's theoretical considerations tend to predominate, indicating a perspective of discussing complexity more through the complexification of reality and thought than by considering the complexity itself of natural and social phenomena.
\end{abstract}

Keywords: Environmental Education. Science Education. Complexities. Educational Process.

\footnotetext{
${ }^{1}$ Mestre em Educação em Ciências (Universidade Federal de Itajubá - UNIFEI). E-mail: brendabragapereira@gmail.com

2 Doutor em Educação (Universidade Estadual Paulista "Júlio de Mesquita Filho" - UNESP)

Professor Associado da Universidade Federal de Itajubá. E-mail: lufesilva@unifei.edu.br

${ }^{3}$ Doutora em Educação (Universidade Federal de São Carlos - UFSCar)

Professora Adjunta da Universidade Federal de Itajubá. E-mail:janainasantos@unifei.edu.br
} 


\section{Resumen}

Existe un número expresivo y calificado de trabajos académicos que abordan las complejidades relacionadas con los temas ambientales a través de discusiones que involucran los campos de la educación ambiental y la educación científica. En este contexto, este trabajo tiene como objetivo, a partir de tesis y disertaciones en el campo de la educación ambiental, investigar los entendimientos sobre las complejidades relacionadas con las ideas que involucran la educación ambiental y la educación científica. Desde un punto de vista metodológico, este es un trabajo de vanguardia. Para la construcción del corpus documental utilizamos el banco de tesis y disertaciones de EArte (Estado del Arte en Educación Ambiental). Seleccionamos veinte tesis y disertaciones para componer el corpus documental de esta investigación. Para el análisis de este material, utilizamos el procedimiento de Análisis de contenido. Construimos cuatro categorías: Pensamiento complejo, Sistemas complejos, Complejidad y complejidades y Prácticas pedagógicas. Podemos señalar que la idea de complejidad, a menudo se apoya en estos trabajos, a partir de las consideraciones de Enrique Leff, Edgar Morin e Ilya Prigogine. Sin embargo, las consideraciones teóricas de Morin tienden a predominar, indicando una perspectiva de discutir la complejidad más a través de la complejidad de la realidad y el pensamiento que considerando la complejidad misma de los fenómenos naturales y sociales.

Palabras clave: Educación ambiental. Enseñanza de las ciencias. Complejidades. Proceso educativo.

\section{Introdução}

Vivemos um aprofundamento da crise ambiental. Essa é uma realidade que se impõe para todos, mesmo aos que ainda insistem na manutenção do sistema atual de produção e organização social. A crise ambiental coloca a nossa sociedade diante da necessidade de repensar e modificar a relação que temos historicamente estabelecido com a natureza.

Leff (2001) é um dos pensadores que tem apresentado uma série de reflexões sobre o fato de a humanidade estar vivenciando um período marcado por uma crise ambiental. Para o autor, uma das características dessa crise está relacionada com as complexidades inerentes as suas causas, efeitos, origens e as formas de amenizar esse quadro.

Importante ressaltar que a crise ambiental tem mobilizado vários setores da sociedade, que procuram contribuir para a compreensão desse quadro envolvido em complexidades. Nesse contexto, destacamos a produção intelectual e prática da área da educação, de modo geral, e da educação ambiental, de modo específico. Segundo Carvalho (2006), a área da educação ambiental tem contribuído sistematicamente com nossas tentativas de compreender a crise ambiental. Nessa perspectiva, Carvalho $(2006,1989)$ indica a relevância da área para nossas tentativas de alterar esse quadro de crise.

Relevante, também, explicitar que a área de educação ambiental (EA) tem elaborado parte de sua produção intelectual e prática a partir de ricas e diversificadas relações com áreas específicas e correlatas do campo da educação como, por exemplo, o da educação em ciências (EC). Lorenzetti e Delizoicov (2006) apontam que há um grupo significativo de teses e dissertações da área, produzidas no Brasil, que se relacionam estreitamente com a área de educação em ciências.

Entendemos que a relação entre essas duas áreas também vem ocorrendo a partir da elaboração de considerações sobre as complexidades inerentes à crise ambiental. Parte desses apontamentos indicam que uma compreensão mais ampla e profunda da crise ambiental deve levar em conta diferentes aspectos dos estudos sobre sistemas complexos, sendo este um campo de investigação relacionado, por exemplo, aos campos das ciências da natureza, ciências humanas e ciências da computação (WATANABE-CARAMELLO; KAWAMURA, 2014).

Nesse contexto, considerando os trabalhos de Vasconcellos e Guimarães (2009), Carvalho, Watanabe-Caramello e Rodriguez-Marin (2015), Brusamarelo et al. (2016) e Strieder et al. (2016), consideramos que já temos uma produção consistente, que tem na complexidade o ponto central na construção de relações entre as áreas da educação ambiental e da educação 
em ciências. A EA, pensada a partir da complexidade, segundo Tavares, Brandão e Schmidt (2009), pode permitir um entendimento mais amplo sobre os aspectos envolvendo a temática ambiental e, ainda, possibilitar uma mudança na forma de pensar e agir frente aos problemas ambientais, a partir do reconhecimento das complexidades inerentes à crise ambiental. Sobre esses aspectos, Guimarães (2007), ressalta que a EA permite, de maneira muito promissora, que as relações entre o ser humano e o meio em que vive possam ser mais bem compreendidas, à medida que o meio ambiente começa a ser entendido e reconhecido a partir de ideias relacionadas aos estudos dos sistemas complexos.

Importante destacar que a literatura sobre sistemas complexos é vasta e variada (MITCHEL, 2009; JACOBSON; LEVIN; KAPUR, 2019; MAMBREY et al., 2020; OSBERG; BIESTA; CILLIERS, 2008; SZEKELY; MASON, 2018). Dentre esses trabalhos, destacamos aqueles que apresentam resultados de estudos sobre diferentes ecossistemas, a partir da ideia de sistemas complexos (MAMBREY et al, 2020). Também chamamos a atenção para os trabalhos que relacionam o campo da educação e os sistemas complexos. Jacobson e Wilensky (2006), por exemplo, ao tratar dos sistemas complexos ressaltam sua importância para o processo de ensino e aprendizagem, em especial, alguns conceitos dos estudos de sistemas complexos para uma compreensão mais ampla sobre o currículo.

Diante dessas considerações temos entendido como relevante a ideia da produção de investigações especificamente voltadas para compreender o termo complexidade nos diferentes trabalhos elaborados por pesquisadores da área da educação ambiental, em especial quando se relacionam com a educação em ciências. Além disso, a área de educação ambiental apresenta uma produção científica consolidada em nosso país, caracterizada pela quantidade, qualidade e diversificação teórica e metodológica. Nesse sentido, o histórico da consolidação dessa área do conhecimento tem levado alguns pesquisadores a indagar sobre o quanto sabemos a respeito dessa produção.

Ainda, chamamos a atenção para a existência de um projeto interinstitucional que visa mapear e sistematizar teses e dissertações da área de educação ambiental produzidas no Brasil. Trata-se de um projeto inovador e, até então, exclusivo em toda a América Latina, conhecido pelo termo EArte (Estado da Arte em Educação Ambiental). O EArte, em 2020, contava com um acervo de 29.672 teses e dissertações.

Esse projeto tem explicitado o crescimento das pesquisas na área da EA. Além disso, a partir desse projeto tem se verificado um esforço constante de alguns pesquisadores no mapeamento dessa extensa produção como, por exemplo, os trabalhos de Souza (2012), Magacho (2017), Dias (2015), Palmieri (2011), Souza (2010), Bitar (2010), Silva e Fernandes (2018), Mazzucato e Bacci (2017) e Mattioli e Kato (2019). Para Ferreira (2002) esse tipo de pesquisa, que busca sistematizar determinados conhecimentos de uma área em específico, são denominadas estado da arte ou estado do conhecimento e uma das suas relevâncias está em contribuir para delimitação das tendências e lacunas de determinado campo do conhecimento. Esse tipo de estudo possibilita que pesquisadores de uma determinada área do conhecimento possam compreender os caminhos percorridos e o que é necessário ainda percorrer.

Nesse contexto, surgiu nosso interesse específico de construir uma investigação que pudesse se voltar para a produção do conhecimento na área de EA. De modo especial, uma pesquisa na qual pudéssemos analisar o conhecimento produzido e divulgado através das teses e dissertações presentes no banco de dados do EArte. Dessa forma, apontamos como objetivo deste trabalho: identificar e analisar compreensões acerca das complexidades em teses e dissertações da área de educação ambiental que se relacionam com a área da educação em ciências.

\section{Complexidades e Educação}


Há uma série de trabalhos nas áreas da educação ambiental e da educação em ciências que são elaborados a partir de considerações sobre sistemas complexos e complexidades. Também, parece-nos evidente que a compreensão da ideia de complexidade é polissêmica. Entretanto, não podemos negar o quanto as ideias de complexidade têm sido fundamentais para a construção de diferentes argumentos que se relacionam com processos educativos.

Há trabalhos que apresentam interessantes e inovadoras possibilidade de ressignificar o ensino de ciências a partir das complexidades inerentes aos problemas ambientais. Nesse contexto, destacamos o trabalho de Watanabe-Caramello e Kawamura (2014). As autoras destacam, no referido trabalho, algumas considerações sobre complexidade, baseadas nas ideias de Edgar Morin, sobretudo no que diz respeito às possibilidades de complexificação da realidade.

Silva (2007), destaca a complexidade dos fenômenos ambientais a partir das ideias desenvolvidas por Ilya Prigogine. Nesse sentido, é interessante destacar que o trabalho de Prigogine (2011) se volta para uma discussão que envolve a complexidade inerente aos fenômenos da natureza.

Carvalho (2006) aponta que as complexidades podem ajudar a ampliar nossa visão sobre educação ambiental. As complexidades propõem questionamentos sobre a sociedade, e, em especial, sobre o modo como nos relacionamos com a natureza, questões ainda pouco abordadas em nossas práticas pedagógicas. Para o autor, as complexidades têm grande importância no âmbito da EA, por permitir problematizações acerca do conceito de natureza, conduzindo os pesquisadores a repensarem, desse modo, a própria EA.

As diferentes relações que podemos construir entre complexidade e processo educativo são vistas por Silva (2007) como uma alternativa para enriquecer nossas práticas pedagógicas voltadas para a temática ambiental. Para o autor, essas relações podem auxiliar a abordar aspectos que, normalmente, não são tratados em sala de aula como, por exemplo, incertezas e controvérsias inerentes à temática ambiental. Esses aspectos podem, ainda, contribuir para construir em sala de aula uma visão mais abrangente da EA, bem como da EC.

Nesse contexto, Silva (2007) indica que a consideração de diferentes aspectos relacionados com as complexidades da crise ambiental em nossos planejamentos educativos, pode tornar mais ricas as nossas práticas pedagógicas, em especial aquelas que relacionam educação ambiental e educação em ciências.

Ainda, temos que as complexidades possuem papel importante não apenas para compreensão da temática ambiental, mas, também, para o planejamento de nossas práticas pedagógicas envolvendo EA e EC. Desse modo, entende-se que o trabalho com as complexidades contribuem para a construção de novas compreensões sobre fenômenos sociais, naturais e sobre a relação sociedade e natureza.

Para Loureiro (2005), as discussões sobre complexidade podem contribuir para a formação de pessoas mais atuantes na sociedade. Pessoas que possam atuar para transformar a sociedade, a partir de uma compreensão mais ampla acerca dos conflitos e incertezas inerentes aos processos sociais.

Já segundo Morales (2007), a educação ambiental, em suas próprias bases epistemológicas, se relaciona a um conhecimento aberto, baseado na dialogicidade e reflexão, não podendo estar aquém das práticas sociais, estas que, a partir da complexidade, buscam se desligar da ideia disciplinar que é imposta na divisão do conhecimento por áreas. Nesse sentido, para Jacobi (2003) a EA articulada às complexidades pode contribuir para que a escola se torne um espaço de reinterpretações de conceitos, diálogos e interações, no qual os alunos terão oportunidade para analisar a natureza juntamente ao seu contexto social, integrando-a a uma realidade complexa. Diante desses argumentos, pode-se perceber que as complexidades apresentam contribuições inovadoras para os processos de ensino e aprendizagem que 
potencializam questionamentos de ordem social, política, histórica, e científica sobre a crise ambiental. Podem, também, auxiliar no enfrentamento dessas questões frente à sociedade e, ainda, permitir uma articulação entre os aspectos da EA e da EC.

\section{Procedimentos metodológicos}

Este trabalho se configura como uma pesquisa de natureza qualitativa e do tipo documental. Segundo Gil (2008), pesquisas desse tipo caracterizam-se por lidar com materiais que não receberam tratamento analítico, ou ainda, que podem ser reelaborados conforme seus objetivos. O corpus documental investigativo deste trabalho foi constituído a partir de teses e dissertações brasileiras que são da área de educação ambiental. Todavia, o nosso corpus de análise é formado por aqueles trabalhos que relacionam educação ambiental e educação em ciências, a partir de discussões relacionadas a ideia de complexidades.

Para a constituição do corpus documental deste trabalho, utilizamos o banco de teses e dissertações do EArte (Estado da Arte em Educação Ambiental - www.earte.net/teses). Esse banco, em 2018, contava com a descrição, incluindo resumos, de 2880 teses e dissertações concluídas de 1981 a 2012. É importante esclarecer que o EArte se trata de um projeto em construção e, por essa razão, até a finalização do processo de coleta de dados dessa pesquisa, realizada no âmbito de um mestrado acadêmico, se encerrou em maio 2018 e, na oportunidade alguns trabalhos defendidos no período do recorte histórico da pesquisa ainda estavam sendo incluídos no banco.

Para a seleção dos trabalhos foi utilizada a ferramenta de busca do site. Utilizamos para busca o termo complex, pois, este permitiu encontrarmos trabalhos variados, desde aqueles contendo a expressão pensamento complexo até aqueles contendo a palavra complexidade. Essa busca nos retornou com 328 indicações de trabalhos.

A próxima etapa consistiu na leitura de todos os 328 resumos, para a definição do corpus documental a partir de três critérios: Inclusão, Exclusão e Dúvida.

- Critério de Inclusão - trabalhos que apresentam uma discussão central sobre complexidades e que se relacionam com a área da educação em ciências. Nesse sentido, incluímos trabalhos que, especificamente, tratam de aspectos de áreas como, por exemplo, ensino de Física, ensino de Biologia e ensino de Química.

- Critério de Exclusão - trabalhos que ou não trazem a complexidade de forma central na discussão proposta, ou trazem o termo como sinônimo de complicado, ou não estabelecem relações com a área de educação em ciências.

- Critério de Dúvidas - trabalhos que mencionam, no resumo, o termo complexidade, relacionam as áreas de educação ambiental e educação em ciências. Todavia, não há elementos mais evidentes sobre a centralidade da discussão envolvendo complexidades.

A partir da leitura dividimos os resumos em três grupos: 1 - 36 trabalhos que constituem o corpus documental; 2 - 262 trabalhos que não constituem o corpus documental; 3 - 30 trabalhos cujos resumos não permitem decidir se constituem ou não o corpus documental.

Tomamos a decisão de procurar e entrar em contato com o texto completo de cada uma das trinta dissertações e/ou teses do grupo de dúvidas para decidir se o trabalho atendia aos critérios estabelecidos nesta investigação. A partir dos trabalhos completos, procuramos verificar se apresentavam ao menos um capítulo no qual o tema da complexidade fosse central no texto. Após essa atividade, decidimos que nenhum dos trinta deveria fazer parte do corpus documental.

A segunda etapa para definição do corpus documental consistiu na procura dos trabalhos completos das 36 teses e dissertações, inicialmente selecionados a partir dos resumos. Para isso, passamos a procurar os arquivos eletrônicos dos trabalhos completos na rede mundial de 
computadores. Nessa etapa, foram encontrados nos repositórios institucionais 23 arquivos eletrônicos contendo trabalhos completos.

Após a leitura desses 23 trabalhos completos, decidimos que seis seriam excluídos por não abordarem complexidades de forma central, dezessete passariam a compor o corpus documental definitivo.

Ainda faltava encontrar treze trabalhos completos. Diante desse contexto, entramos em contato com os autores destes trabalhos, sendo que dez deles a partir de e-mail, e três via ferramenta de contato da plataforma Lattes. Dos dez autores que contatamos por e-mail, quatro enviaram o arquivo eletrônico do trabalho completo. Após a leitura, decidimos que dois deles passariam a compor o corpus documental definitivo da investigação, os outros dois seriam descartados. Dos três autores que contatamos diretamente via plataforma Lattes, dois enviaram o trabalho, porém, após a leitura completa, optamos por excluí-los. Nosso corpus documental, então, estava formado por dezenove trabalhos completos. Dez trabalhos haviam sido excluídos do corpus documental definitivo.

Decidimos entrar novamente em contato com os seis autores que não responderam a mensagem enviada por e-mail. Para isso, utilizamos a ferramenta de contato da plataforma Lattes. Um autor enviou o arquivo eletrônico do trabalho completo. Após a leitura, decidimos que este também passaria a compor o corpus definitivo da investigação. Dessa forma, nosso corpus documental ficou formado por vinte trabalhos completos. Dez trabalhos haviam sido excluídos.

Os seis trabalhos que não conseguimos encontrar finalmente foram excluídos do corpus documental definitivo. Ou seja, dezesseis trabalhos foram excluídos e vinte compuseram o corpus documental da investigação, sendo catorze provenientes de trabalho de mestrado (denominados pela letra $\mathrm{D}$ seguida de número) e seis de trabalhos de doutorado (denominado pela letra $\mathrm{T}$, seguida de número). $\mathrm{O}$ Quadro 1 apresenta todos os trabalhos que foram selecionados para análise, organizados de forma cronológica, além disso, os identificadores dos trabalhos foram atribuídos na primeira etapa de definição do corpus dessa investigação, quando havia 36 trabalhos incluídos. Por isso, é possível perceber que a numeração dos identificadores não obedece exatamente a uma ordem.

\begin{tabular}{|c|c|c|c|}
\hline Título & Identificador & Autor & Ano \\
\hline $\begin{array}{c}\text { Ecossistemas terrestres naturais como ambientes } \\
\text { para as atividades de ensino de ciências }\end{array}$ & D19 & Tatiana Seniciato & 2002 \\
\hline $\begin{array}{c}\text { A dinâmica de um museu de ciências naturais: a } \\
\text { transformação paradigmática do Museu } \\
\text { Zoobotânico Augusto Ruschi }\end{array}$ & D2 & Flavia Biondo Da Silva & 2005 \\
\hline $\begin{array}{c}\text { O paradigma complexo: a energia e a educação } \\
\text { Uma ecologia de base complexa }\end{array}$ & D6 & $\begin{array}{c}\text { Douglas Ricardo } \\
\text { Slaughter Nyimi }\end{array}$ & 2006 \\
\hline $\begin{array}{c}\text { Elementos para uma abordagem temática: a } \\
\text { questão das águas e sua complexidade }\end{array}$ & D8 & Wyllys Abel Farkatt \\
Tabosa & Giselle Watanabe & 2007 \\
\hline $\begin{array}{c}\text { Caramello } \\
\text { professores de Biologia e a prática docente a } \\
\text { partir da educação ambiental }\end{array}$ & D14 & Mônica Lopes Folena \\
de Araújo & 2008 \\
\hline \begin{tabular}{c} 
Análise das contribuições do educar pela pesquisa \\
\hline
\end{tabular} & D26 & Rosangela Ferreira & 2008 \\
\hline
\end{tabular}




\begin{tabular}{|c|c|c|c|}
\hline no estudo das fontes de energia & & Prestes & \\
\hline $\begin{array}{l}\text { Biocidadania: uma proposta de projeto em } \\
\text { educação ambiental que possibilita o diálogo } \\
\text { entre disciplinas do ensino médio }\end{array}$ & D28 & $\begin{array}{l}\text { Claudine de Andrade } \\
\text { Silvestre }\end{array}$ & 2008 \\
\hline $\begin{array}{l}\text { A prática da transversalidade na formação de } \\
\text { professores: reflexos no ensino básico }\end{array}$ & D1 & $\begin{array}{l}\text { Fabiane de Matos } \\
\text { Araújo }\end{array}$ & 2009 \\
\hline $\begin{array}{l}\text { Física Ambiental e teoria da complexidade: } \\
\text { possibilidades de ensino na educação básica }\end{array}$ & D3 & Miguel Jorge Neto & 2009 \\
\hline $\begin{array}{l}\text { O saber ambiental na formação dos professores de } \\
\text { Biologia }\end{array}$ & $\mathrm{T} 2$ & $\begin{array}{l}\text { Simone Sendin Moreira } \\
\text { Guimarães }\end{array}$ & 2009 \\
\hline $\begin{array}{l}\text { Informática na educação e o ensino de ciências } \\
\text { naturais: contribuições para a educação ambiental } \\
\text { no contexto amazônico }\end{array}$ & D17 & $\begin{array}{l}\text { Rosa Eulália Vital Da } \\
\text { Silva }\end{array}$ & 2009 \\
\hline $\begin{array}{l}\text { A educação ambiental no ensino de ciências: } \\
\text { formação, prática e transversalidade }\end{array}$ & D4 & $\begin{array}{l}\text { Tatyanna de Melo } \\
\text { Afonso }\end{array}$ & 2011 \\
\hline $\begin{array}{c}\text { Dinâmica natural e ensino de Química para jovens } \\
\text { e adultos: saberes e práticas de uma inovação } \\
\text { curricular }\end{array}$ & D18 & $\begin{array}{l}\text { Silvana Maria Correa } \\
\text { Zanini }\end{array}$ & 2011 \\
\hline $\begin{array}{l}\text { Projetos de trabalho em educação ambiental: uma } \\
\text { alternativa transdisciplinar à prática docente. }\end{array}$ & D5 & $\begin{array}{l}\text { Adelmo Fernandes De } \\
\text { Araújo }\end{array}$ & 2011 \\
\hline $\begin{array}{l}\text { Aspectos da complexidade: contribuições da } \\
\text { Física para a compreensão do tema ambiental }\end{array}$ & $\mathrm{T} 1$ & $\begin{array}{l}\text { Giselle Watanabe } \\
\text { Caramello }\end{array}$ & 2012 \\
\hline $\begin{array}{c}\text { Perspectivas da visão transdisciplinar holística e } \\
\text { suas contribuições para a construção de uma } \\
\text { sociedade ecológica: o caso da Ecovila Terra Una, } \\
\text { Liberdade - MG }\end{array}$ & D12 & $\begin{array}{l}\text { Kelly Daiane Savariz } \\
\text { Bôlla }\end{array}$ & 2012 \\
\hline $\begin{array}{c}\text { Educação ambiental como disciplina na formação } \\
\text { dos biólogos: um estudo de caso na Universidade } \\
\text { Federal de Uberlândia }\end{array}$ & $\mathrm{T} 4$ & $\begin{array}{l}\text { Melchior Jose Tavares } \\
\text { Junior }\end{array}$ & 2012 \\
\hline $\begin{array}{c}\text { Saberes ambientais: pontes de convergência que } \\
\text { enagem no espaço de convivência da formação de } \\
\text { educadores }\end{array}$ & T5 & Robledo Lima Gil & 2012 \\
\hline $\begin{array}{c}\text { A cigarra e a formiga: a educação ambiental e o } \\
\text { ensino de ciências em escolas públicas de Brasília } \\
\text { - Distrito Federal }\end{array}$ & T6 & $\begin{array}{l}\text { Zara Faria Sobrinha } \\
\text { Guimaraes }\end{array}$ & 2012 \\
\hline
\end{tabular}

Quadro 1 - Informações sobre as Teses e Dissertações que foram submetidas à análise do texto completo. Fonte: a autora

A análise consistiu da leitura dos trabalhos completos, a fim de compreender os significados que o termo complexidade apresenta nessas teses e dissertações. Para essa análise, foi utilizada a técnica da Análise de Conteúdo, tal como proposta por Bardin (1979, p. 42). Segundo a autora, a Análise de Conteúdo:

Representa um conjunto de técnicas de análise das comunicações que visam a obter, por procedimentos sistemáticos e objetivos de descrição do conteúdo das mensagens, 
indicadores (quantitativos ou não) que permitam a inferência de conhecimentos relativos às condições de produção e recepção dessas mensagens.

As categorias definidas a priori para analisar as diferentes compreensões sobre complexidade foram: Pensamento complexo, Sistemas Complexos e Complexificação. E a posteriori: Complexidades e Práticas Pedagógicas. A constituição das categorias seguiu a estratégia de localizar, contabilizar e sistematizar os núcleos de sentido em agrupamentos construídos por semelhança de significados.

\section{Complexidades e o processo educativo em teses e dissertações brasileiras}

Nesta seção, apresentamos resultados da nossa investigação. Elaboramos quatro categorias de análise: Pensamento complexo, Sistemas Complexos e Complexificação e Complexidades e Práticas Pedagógicas. Essas categorias estão diretamente relacionadas com compreensões sobre as complexidades relacionadas às ideias que envolvem educação ambiental e educação em ciências em teses e dissertações da área de educação ambiental.

A categoria Pensamento complexo se refere a uma nova maneira de pensar frente ao mundo. Essa categoria é constituída a partir de três agrupamentos de núcleos de sentido, relacionados diretamente aos trabalhos de Morin (2015): Princípio Dialógico, Princípio da Recursão Organizacional e Princípio Hologramático. Esses agrupamentos estão sistematizados no Quadro 2, como segue.

\begin{tabular}{|c|c|c|}
\hline Agrupamentos & Teses e Dissertações & Excertos \\
\hline Princípio dialógico & $\mathrm{D} 1, \mathrm{D} 2, \mathrm{D} 17, \mathrm{D} 19, \mathrm{D} 28$ & $\begin{array}{l}\text { Essas relações, por sua vez, podem ser mais facilmente } \\
\text { observadas, ou mesmo entendidas, em um ambiente onde } \\
\text { elas efetivamente acontecem, de modo a se evitar a } \\
\text { fragmentação e a possível ideia de independência entre } \\
\text { aquilo que é vivo e aquilo que não é. O ensino das ciências } \\
\text { naturais deve privilegiar a complexidade da natureza e a } \\
\text { integralidade de seus fenômenos, pois a } \\
\text { compartimentalização para fins didáticos parece não } \\
\text { contribuir para o entendimento do mundo tal qual ele se } \\
\text { apresenta. (D19, 2002, p. 93) }\end{array}$ \\
\hline $\begin{array}{l}\text { Princípio da recursão } \\
\text { organizacional }\end{array}$ & $\mathrm{D} 1, \mathrm{D} 4, \mathrm{D} 5$ & $\begin{array}{l}\text { O modelo de escola vigente tem promovido um ensino } \\
\text { com disciplinas estanques e isoladas, o que impossibilita } \\
\text { trazer para seu bojo uma realidade socioambiental } \\
\text { formada por pluralidades de complexos, incertos e não } \\
\text { lineares a qual pertence. Assim, a escola parece não estar } \\
\text { conseguindo formar em seus/suas alunos/as } \\
\text { subjetividades, de modo que eles/elas sejam capazes de } \\
\text { interpretar, agir e interferir responsavelmente } \\
\text { comprometidos/as com a natureza, da qual o ser humano } \\
\text { é parte constituída e constituinte. (D5, 2011, p. 14) }\end{array}$ \\
\hline Princípio hologramático & T2, D4, D5 & $\begin{array}{l}\text { Sendo assim, o sistema não é a soma de partes de um } \\
\text { sistema que o torna complexo, mas a propriedade surgida } \\
\text { do seu funcionamento, uma vez que a fragmentação de } \\
\text { cada parte do sistema não levará ao entendimento do todo, } \\
\text { ao contrário, tornará o sistema incompleto, inacabado. É } \\
\text { esta lógica que se confronta ao paradigma da }\end{array}$ \\
\hline
\end{tabular}




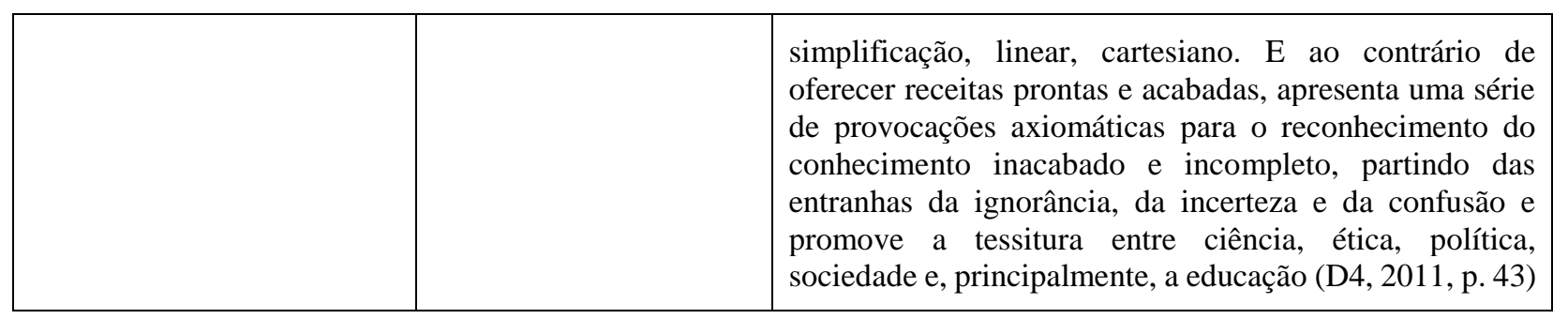

Quadro 4 - O pensamento complexo no processo educativo.

Fonte: a autora

Com relação ao agrupamento Princípio Dialógico, buscamos identificar, nos trabalhos, trechos que explicitavam inter-relações que mencionassem a dualidade no contexto da unidade (como a ideia de ordem e desordem de Morin). Cinco trabalhos, dos vinte que foram analisados, apresentam considerações relacionadas com essa ideia em suas discussões sobre complexidade.

O excerto do trabalho D19 (vide Quadro 2), que exemplifica esse agrupamento, apresenta a ideia de não fragmentação e de independência na natureza. $\mathrm{O}$ autor também destaca, nesse trecho que selecionamos, a relevância de abordar aspectos da complexidade no ensino de ciências.

Há, também, nos trabalhos analisados trechos que possibilitaram construir o agrupamento denominado Princípio da Recursão Organizacional. Nesses trechos, prevalece a ideia de que o objeto age sobre o observador, assim como o observador age no objeto. Três investigações, das vinte analisadas, apresentaram núcleos de sentido voltados para essa ideia.

O excerto trazido de D5, apresentado no Quadro 2, para exemplificar esse agrupamento, demonstra a ideia de que o processo educativo, para contemplar a complexidade, deve considerar a subjetividade necessária para que os alunos possam se ver como parte constituída e constituinte da natureza, na qual eles agem e interferem. Essa ideia articula-se com a do princípio da recursão organizacional, na qual Morin (2015), defende que, da mesma maneira que agimos e interferimos sobre a natureza, somos parte dela e dessa forma ela age e interfere em nós também, em um processo dinâmico.

Com relação ao agrupamento Princípio Hologramático, buscamos, nos trabalhos analisados, discussões que considerassem a ideia de parte e todo como relevantes para o processo educativo. Três trabalhos, dos vinte que foram analisados apresentaram essa ideia em suas discussões.

No trecho de D4, apresentado no Quadro 2, como exemplo desse agrupamento, podemos destacar a ideia de parte e todo, além disso, o trabalho destaca a compreensão de que a educação precisa passar a considerar essas noções que constroem o pensamento complexo, definido por Morin (2015), para que possa compreender e agir sobre a crise planetária que vivemos.

Outra categoria considerada nesse trabalho é a denominada Sistemas Complexos. Dois agrupamentos foram elaborados a partir dessa categoria, sendo esses: Conteúdo Sistemas e Abordagem Sistêmica. Sobre o agrupamento conteúdo sistemas, trata-se da ideia de sistemas elaborada por Prigogine (2011), ou sistemas abertos, como definido por Morin (2015), que são apresentados como conteúdos escolares. Já o agrupamento Abordagem sistêmica refere-se, também, à noção de sistemas de Prigogine (2011) e Morin (2015), porém, a partir de uma abordagem que se relaciona à ideia de um novo fazer científico.

Esses agrupamentos estão sistematizados no Quadro 3.

\begin{tabular}{|l|l|l|}
\hline Agrupamentos & Teses e Dissertações & Excertos \\
\hline
\end{tabular}




\begin{tabular}{|c|c|l|}
\hline Conteúdo Sistemas & D1, T1, D3, D4, D18 & $\begin{array}{l}\text { Nesse sentido, nos parece fundamental promover } \\
\text { uma mudança nos discursos escolares, de modo que } \\
\text { haja uma problematização dos fenômenos naturais } \\
\text { pautados na realidade complexa. Isso significa, por } \\
\text { exemplo, considerar as dificuldades encontradas } \\
\text { pela ciência ao discutir sistemas complexos, abertos } \\
\text { e dinâmicos, como é o caso da maioria das relações } \\
\text { estabelecidas no sistema terrestre (T1, 2012, p. 53). }\end{array}$ \\
\hline Abordagem sistêmica & D1, D6, D8, T4, T5, \\
D28 & $\begin{array}{l}\text { O pensar transversal parte, portanto, de um pensar } \\
\text { complexo, tendo assim a necessidade de abordar o } \\
\text { conhecimento a partir de uma perspectiva sistêmica } \\
\text { e complexa, levando em consideração inúmeros } \\
\text { aspectos e dimensões, onde o enfoque didático } \\
\text { interdisciplinar é uma condição inevitável para a } \\
\text { prática da transversalidade, apesar de ser este um } \\
\text { desafio para a escola fragmentada tradicional, na } \\
\text { qual ainda persiste o reducionismo do pensamento. } \\
\text { (D1, 2009, p. 92) }\end{array}$ \\
\hline
\end{tabular}

Quadro 3 - Os sistemas complexos no processo educativo

Fonte: a autora

No agrupamento Conteúdo Sistemas estão sistematizados os trechos dos trabalhos nos quais o conceito de sistemas é abordado como conteúdo escolar, ou considerado importante nesse mesmo sentido. Cinco dos vinte trabalhos analisados apresentaram essa ideia em seu texto.

No trecho de T1, apresentado no Quadro 3, como exemplo desse agrupamento, podemos destacar considerações do autor sobre a relevância de se abordar ideias relacionadas à complexidade no processo educativo, em especial aquelas que enfocam os sistemas abertos, dinâmicos e complexos. Segundo o autor de T1, o próprio sistema terrestre se configura num sistema complexo.

No agrupamento denominado Abordagem Sistêmica foram organizados trechos dos trabalhos nos quais se explicita essa ideia de abordagem, ou ainda, considerações que apresentam inúmeros aspectos e dimensões de um determinado aspecto da realidade. Seis dos vinte trabalhos submetidos à análise apresentaram essa discussão em seus textos. $\mathrm{O}$ exemplo apresentado no Quadro 3, referente à D1, como forma de exemplificar esse agrupamento, destaca a importância da abordagem sistêmica para o pensar de forma transversal. Há, ainda, considerações sobre os desafios de abordar ideias dessa natureza na escola.

A categoria Complexificação conta com dois agrupamentos: Complexidade Ambiental" e Complexificação do Conhecimento.

A ideia de Complexidade Ambiental está diretamente relacionada aos apontamentos de Leff (2001), sobretudo quando o autor destaca que a compreensão dos problemas ambientais deve passar por diferentes vias de complexificação da realidade.

Já o agrupamento denominado Complexificação do Conhecimento deve ser entendido na mesma perspectiva de García (1998). Nesse agrupamento, a complexificação do conhecimento tem por objetivo a integração dos saberes, uma construção que vise articular os conhecimentos antes fragmentados, não apenas pelos campos disciplinares, mas também os conhecimentos cotidianos, escolares e científicos, de modo que o sujeito possa agir e solucionar problemas. Esses agrupamentos estão sistematizados no Quadro 4. 


\begin{tabular}{|c|c|c|}
\hline Agrupamentos & Teses e Dissertações & Excertos \\
\hline Complexidade ambiental & $\mathrm{T} 2, \mathrm{D} 5, \mathrm{D} 28$ & $\begin{array}{l}\text { O enfrentamento da crise supõe uma Educação } \\
\text { Ambiental (EA) transformadora, emancipatória, } \\
\text { embasada na complexidade e na ecologia profunda } \\
\text { (deep ecology), pois, a educação representa um } \\
\text { forte mecanismo de transição para uma nova } \\
\text { racionalidade pautada no "saber ambiental", ao qual } \\
\text { o ensino de biologia não pode ficar alheio. (D28, } \\
2008, \text { p. 14) }\end{array}$ \\
\hline $\begin{array}{l}\text { Complexificação do } \\
\text { conhecimento }\end{array}$ & $\mathrm{T} 1, \mathrm{D} 8, \mathrm{~T} 5, \mathrm{D} 26$ & $\begin{array}{l}\text { Para ele, as questões ambientais são suficientemente } \\
\text { diversificadas para estruturar o saber escolar } \\
\text { enquanto uma ciência social integradora. Entender } \\
\text { o mundo sob esses aspectos só é possível se houver } \\
\text { a transição de uma forma simples a outra mais } \\
\text { complexa, o que significa complexificar o } \\
\text { conhecimento (D8, 2008, p. 22) }\end{array}$ \\
\hline
\end{tabular}

Quadro 4 - A complexificação no processo educativo Fonte: a autora

Três das vinte investigações analisadas apresentam trechos que podem ser organizados no agrupamento Complexidade Ambiental. Nesse contexto, o exemplo apresentado no Quadro 4, referente à D28, explicita a utilização das ideias de Leff (2001) sobre a complexificação como via para a construção de um saber ambiental. Nesse trabalho, a ideia de complexidade ambiental é utilizada para relacionar as áreas de ensino de biologia e de educação ambiental.

No agrupamento Complexificação do Conhecimento estão organizados trechos dos trabalhos que destacam a necessidade de utilizar as ideias de complexidade para melhor compreender as relações entre conhecimentos escolares, cotidianos e científicos. Quatro das vinte investigações analisadas apresentam essa ideia em suas discussões. No trecho de D8, apresentado no Quadro 4, como exemplo desse agrupamento, podemos destacar que as questões ambientais, devido à sua diversidade, podem permitir a complexificação do conhecimento. De fato, conforme aponta García (1998), os problemas ambientais são um assunto privilegiado para a complexificação do conhecimento.

Para formar a categoria Complexidades e Práticas Pedagógicas consideramos dois agrupamentos: Articulação entre EA e EC e Pedagogia da Complexidade. No agrupamento Articulação entre EA e EC organizamos aqueles trechos que explicitam a ideia de que, a partir das complexidades, é possível relacionar as áreas de educação em ciências e educação ambiental. Importante destacar que Loureiro (2005) indica que a EA, perante as complexidades, exige uma articulação com a EC, uma vez que o modo como se compreende as ciências tornase determinante para o modo como nos relacionamos com a natureza.

Já o agrupamento Pedagogia da Complexidade, conforme Marandola e Takeda (2004), refere-se à ideia de uma pedagogia que objetive articular o maior número de perspectivas na busca do conhecimento. Nesse sentido, essa é uma perspectiva pedagógica que visa promover uma visão múltipla, complexa e dinâmica do ambiente e do conhecimento. As ideias que formam a base da pedagogia da complexidade têm seus fundamentos em Edgar Morin. É importante, também, destacar que a pedagogia da complexidade, por trazer como princípio a ideia de diálogo entre as múltiplas perspectivas do conhecimento, abarca as noções de inter e transdisciplinaridade. Esses agrupamentos estão sistematizados no Quadro 5. 


\begin{tabular}{|c|c|c|}
\hline Agrupamentos & Teses e Dissertações & Excertos \\
\hline Articulação entre EA e EC & $\begin{array}{c}\mathrm{D} 1, \mathrm{~T} 1, \mathrm{D} 3, \mathrm{~T} 2, \mathrm{~T} 4, \mathrm{D} 18, \\
\mathrm{D} 19, \mathrm{~T} 6\end{array}$ & $\begin{array}{l}\text { Diante de suas complexidades, o ensino de ciências } \\
\text { e a educação ambiental poderão ser trabalhados por } \\
\text { meio de modos de pensar e de tratar a natureza } \\
\text { juntamente com os conhecimentos científicos ou } \\
\text { poderão utilizar tais conhecimentos na busca de } \\
\text { contribuição para suas práticas sociais, pois ambos } \\
\text { participarão de um mesmo construto: o } \\
\text { conhecimento humano (T6,2012, p. 29) }\end{array}$ \\
\hline $\begin{array}{l}\text { Pedagogia da } \\
\text { complexidade }\end{array}$ & $\begin{array}{c}\mathrm{D} 1, \mathrm{D} 2, \mathrm{~T} 1, \mathrm{~T} 2, \mathrm{D} 4, \mathrm{~T} 3 \\
\mathrm{D} 5, \mathrm{D} 8, \mathrm{D} 12, \mathrm{~T} 4, \mathrm{D} 14, \\
\mathrm{~T} 5, \mathrm{D} 17, \mathrm{D} 18, \mathrm{D} 19, \mathrm{~T} 6 \\
\mathrm{D} 28\end{array}$ & $\begin{array}{l}\text { É importante levar em conta que o que se pretende } \\
\text { é uma formação que seja capaz de levar os } \\
\text { discentes a desenvolver a competência para } \\
\text { contextualizar os conhecimentos, integrando-os } \\
\text { em seu conjunto (MARTINAZZO, 2002). Essa } \\
\text { formação inicial é essencial para que a pedagogia } \\
\text { da complexidade e consequentemente a discussão } \\
\text { acerca da crise ambiental, a partir dela, possam } \\
\text { começar na educação básica, com a intervenção do } \\
\text { professor, que reformula o conteúdo de suas } \\
\text { matérias, tomando como objetivo os problemas } \\
\text { socioambientais do mundo atual (LEFF, 2001), } \\
\text { porém, para que isso aconteça, o investimento em } \\
\text { uma formação de qualidade é imprescindível. (T2, } \\
\text { 2009, p. 178) }\end{array}$ \\
\hline
\end{tabular}

Quadro 5 - Complexidades e Práticas Pedagógicas

Fonte: a autora

Sobre o agrupamento articulação entre EA e EC identificamos, nas teses e dissertações, trechos em que a complexidade é apresentada na perspectiva de elaborar relações entre essas duas áreas do conhecimento. Oito das vinte investigações analisadas apresentam essa ideia em suas discussões. Nesse contexto, o exemplo apresentado no Quadro 5 destaca a ideia de que tanto o ensino de ciências como a educação ambiental podem partir de um mesmo ponto sendo este as complexidades. Nesse sentido, as ideias de Loureiro (2006) são corroboradas, na medida em que se vê uma aproximação entre essas duas áreas pela perspectiva da construção do conhecimento que está relacionada ao modo como nos relacionamos com a natureza.

No agrupamento Pedagogia da Complexidade estão reunidos trechos dos trabalhos no qual a complexidade é apresentada como uma perspectiva de promoção da inter e/ou transdisciplinaridade, uma vez que a ideia da pedagogia da complexidade se relaciona diretamente com a articulação dos conhecimentos das diferentes áreas. Dezessete dos vinte trabalhos analisados apontaram para essa perspectiva. No excerto apresentado no Quadro 5, podemos ver que há uma menção direta à pedagogia da complexidade relacionada à ideia de integração entre os conhecimentos. Essa ideia, em concordância com Marandola e Takeda (2004), é a base do que estamos chamando de pedagogia da complexidade.

\section{Considerações Finais}

As análises realizadas a partir das teses e dissertações indicam alguns elementos relevantes sobre a maneira como as complexidades estão sendo compreendidas na área da educação ambiental, em especial quando se relacionam com a área da educação em ciências. 
De modo geral, parece-nos relevante indicar que as diferentes considerações que abordam complexidades ligadas ao processo educativo apontam para um caminho promissor e inovador para pensarmos nossas práticas pedagógicas do ponto de vista teórico e metodológico.

Para a análise das teses e dissertações foram construídas as seguintes categorias: Pensamento Complexo, Sistemas Complexos, Complexificação e Complexidades e Práticas Pedagógicas.

Sobre a categoria Pensamento Complexo, oito dos vinte trabalhos analisados se relacionam com a ideia de que a construção do pensamento complexo é importante para o processo educativo. Destacamos que cinco trabalhos se voltaram para a importância de considerar o princípio dialógico, ou seja, as inter-relações entre os conceitos para o processo educativo; três trabalhos voltaram-se para a relevância de abordar o princípio da recursão organizacional, ou seja, a ideia de que o sujeito interfere no meio assim como o meio interfere no sujeito, para o processo educativo; e três investigações destacaram a importância de considerar o princípio hologramático no processo educativo.

Com relação à categoria Sistemas Complexos, dez das vinte teses e dissertações analisadas abordaram, de alguma forma, essa ideia ao se referirem ao processo educativo. Cinco trabalhos consideram a ideia de sistemas como um conteúdo a ser abordado no contexto escolar e seis investigações apontaram para a ideia de uma abordagem sistêmica, esta que se relaciona a uma abordagem que permite uma nova visão de ciência no processo educativo.

Sobre a categoria Complexificação, sete dos vinte trabalhos analisados apresentaram alguma ideia que se relacionasse a essa categoria no processo educativo. Há três trabalhos que destacam a importância de considerar a complexidade ambiental e as vias de complexificação. Há, ainda, quatro trabalhos que explicitam que a complexificação pode ocorrer a partir da articulação dos conhecimentos escolares, científicos e cotidianos, como relevantes para o processo educativo.

A partir da categoria Complexidades e Práticas Pedagógicas podemos dizer que dezoito teses e dissertações destacam alguma ideia voltada para práticas pedagógicas que se relacionam com diferentes aspectos da complexidade. Oito trabalhos destacam a complexidade como forma de articular a EA e a EC no processo educativo. Há, ainda, dezessete trabalhos que apontam para o que denominamos de pedagogia da complexidade.

É relevante destacar que um mesmo trabalho pôde estar em diferentes agrupamentos e categorias, o que nos indica que foram encontrados significados distintos para Complexidades em uma mesma investigação. Esse fato é importante e nos indica uma tendência, nos trabalhos analisados, no sentido de construir relações teóricas a partir de diferentes referenciais que tratam da complexidade. Desse modo, não é raro encontrar trabalhos que apresentem discussões orientadas pelas ideias de Morin, Leff e Prigogine. Todavia, os trabalhos de Morin parecem estar mais direcionados para um processo de complexificação da realidade. Já os trabalhos de Prigogine parecem se voltar mais para a complexidade inerente aos fenômenos físicos.

Todavia, chama ainda a atenção o fato de que há trabalhos que relacionam, de modo muito próximo, as ideias de Morin e Leff. Entretanto, Leff (2001), ao discutir as vias de complexificação da realidade, apresenta críticas ao trabalho de Morin. Parece-nos que esse é um elemento que precisa ser considerado na construção teórica das nossas teses e dissertações. Ou seja, parece-nos importante que os trabalhos da área de EA, que se relacionam com a EC, possam considerar algumas das diferenças teóricas entre esses autores, em especial quando se trata de vias de complexificação da realidade.

Os trabalhos analisados nos permitem apontar que são frequentes as menções à perspectiva de utilizar as complexidades para repensar metodologicamente nossas práticas pedagógicas. Podemos indicar que, nesses trabalhos, defende-se a ideia de que as complexidades apresentam caminhos promissores para repensarmos metodologicamente nosso trabalho em sala de aula. Nesse sentido, os trabalhos analisados indicam explicitamente as 
diferentes contribuições advindas da obra de Edgar Morin. O que destaca uma perspectiva das complexidades como aliada da educação em ciências e da educação em geral.

Essas considerações nos indicam os caminhos percorridos pela área de educação ambiental ao se articular com a área de educação em ciências a partir das complexidades, o que é relevante, uma vez que se entende a complexidade como uma forma de aproximação dessas áreas. Além disso, nos mostra algumas lacunas que necessitam de um olhar mais aprofundado de pesquisa, por exemplo, entender como os diferentes referenciais têm sido abordados nessas produções.

Por fim, consideramos relevante, a partir dessa investigação, aprofundar a análise das relações que são elaboradas entre as áreas de educação ambiental e educação em ciências a partir das complexidades. Contudo, pensamos ser importante ampliar e diversificar os documentos a serem analisados. Nesse contexto, entendemos ser necessário construir uma investigação que também se volte para artigos publicados em periódicos e anais de eventos importantes dessas duas áreas do conhecimento.

\section{Referências}

BARDIN, L. Análise de conteúdo. Lisboa: Ed. 70, 1979.

BITAR, A. L. Pesquisa em educação ambiental: a atividade de campo em teses e dissertações. 2010. 171 f. Dissertação (Mestrado em Educação) - Universidade Estadual Paulista Júlio de Mesquita Filho, Rio Claro, 2010.

BRUSAMARELO, D., DA LUZ; A. R., MIRANDA, D. G.; LONGHIN, S. R.; DE ASSIS PIRES, L. L. A educação ambiental no contexto da evolução da ciência, tecnologia e sociedade. Revista HISTEDBR On-line, Campinas, v. 16, n.69, p. 336-346, 2016.

CARVALHO, L. M. D. A temática ambiental e o processo educativo: dimensões e abordagens. In: CINQUETTI, H. S.; LOGAREZZI, A. Consumo e resíduo: fundamentos para o trabalho educativo. São Carlos: EdUFSCar, 2006. p. 19-41.

CARVALHO, L. M. A temática ambiental e a escola de $1^{\circ}$ grau. 1989. 286 f. Tese (Doutorado em Educação) - Faculdade de Educação, Universidade de São Paulo, São Paulo, 1989.

CARVALHO, F. R.; WATANABE, G.; RODRÍGUEZ-MARÍN, F. Os níveis de progressão nas formulações dos alunos frente às questões socioambientais. In: ENPEC - ENCONTRO NACIONAL DE PESQUISA EM EDUCAÇÃO EM CIÊNCIAS, X ENPEC, 2015, Águas de Lindóia, SP. Anais X ENPEC, Disponível em: http://www.abrapecnet.org.br/enpec/x-enpec/anais2015/lista_area_06.htm.

DIAS, C. M. Práticas pedagógicas de educação ambiental em áreas protegidas: um estudo a partir de dissertações e teses (1981-2009). 2015. 208 f. Tese (Doutorado em Ensino de Ciências e Matemática) - Faculdade de Educação, Universidade Estadual de Campinas, Campinas, 2015.

Ferreira, N. S. D. A. As pesquisas denominadas" estado da arte". Educação \& sociedade, 23(79), 257$272,2002$.

GARCÍA, J. E. Hacia una teoría alternativa sobre los contenidos escolares. Sevilla, Espanha: Díade, 1998.

GIL, A. C. Métodos e Técnicas de pesquisa social. 6 ed. São Paulo: Atlas, 2008. 
GUIMARÃES, M. Educação Ambiental: participação para além dos muros da escola. In: MELLO, S. S.; TRAJBER, R. (Coord.) Vamos cuidar do Brasil: conceitos e práticas em educação ambiental na escola. Brasília: MEC/MMA, 2007.

JACOBI, P. R. Educação ambiental, cidadania e sustentabilidade. Cadernos de pesquisa, São Paulo, [s.v], n. 118, p. 189-205, mar. 2003.

JACOBSON, M. J.; LEVIN, J. A.; KAPUR, M. Education as a complex system: Conceptual and methodological implications. Educational Researcher, [s.1], v. 48, n. 2, p. 112-119, 2019.

JACOBSON, M.; J.; WILENSKY, U. Complex systems in education: Scientific and educational importance and implications for the learning sciences. The Journal of the learning sciences, London, v. 15, n. 1, p. 11-34, 2006.

LEFF, E. Epistemologia Ambiental. São Paulo: Cortez, 2001.

LORENZETTI, L.; DELIZOICOV, D. Educação Ambiental: um olhar sobre Dissertações e Teses. Revista Brasileira de Pesquisa em Educação em Ciências, Belo Horizonte, v. 6, n. 2, p. 1-21 Maio/Ago. 2006. Disponível em:

<https://periodicos.ufmg.br/index.php/rbpec/article/view/4047/2611>. Acesso em: 20 jun. 2021.

LOUREIRO, C. F. B. Complexidade e dialética: contribuições à práxis política e emancipatória em educação ambiental. Educ. Soc., Campinas, v. 26, n. 93, p.1473-1494, 2005.

LOUREIRO, C. F. B. Trajetória e Fundamentos da Educação Ambiental. São Paulo: Cortez, 2006.

MAGACHO, L. N. Pesquisa em educação ambiental e movimentos sociais: um estudo sobre teses e dissertações brasileiras. 2017. 145 f. Dissertação (Mestrado em Educação) - Universidade Estadual Paulista, Rio Claro, 2017.

MAMBREY, S. et al. The impact of system specifics on systems thinking. Journal of Research in Science Teaching, New Jersey, v. 57, n. 10, p. 1632-1651, 2020.

MARANDOLA JR, E.; TAKEDA, M. Pedagogia ambiental e pedagogia da complexidade: da tríade à Educação Humanista. Scripta Nova: revista electrónica de geografía y ciencias sociales, Barcelona, v. 8, n. 164, [s.p], Maio 2004.

MATTIOLI, C. K. K.; KATO, D. S. Desastres Ambientais e Educação Ambiental: análise das pesquisas acadêmicas do banco de teses e dissertações do EArte no período de 1981 a 2016. Pesquisa em Educação Ambiental, Rio Claro, v. 14, n. 2, p. 72-93, 2019.

MAZZUCATO, E.; BACCI, D. C. Estado da arte e contribuição das geociências para a Educação Ambiental. Pesquisa em Educação Ambiental, Rio Claro, v. 12, n. 2, p. 141-161, 2017.

MITCHELL, M. Complexity: A guided tour. Nova York, Estados Unidos da América: Oxford University Press, 2009.

MORALES, A. G. M. A formação do profissional educador ambiental: reflexões, possibilidades e constatações no curso de especialização da UFPR. 2007. 253 f. Tese (Doutorado em Meio Ambiente e Desenvolvimento) - Universidade Federal do Paraná, Curitiba, 2007.

MORIN, E. Ciência com consciência. Barcelona: Anthropos, 2005. 
MORIN, E. Introdução ao pensamento complexo. Tradução de: Eliane Lisboa. Porto Alegre: Sulina, 2015.

OSBERG, D.; BIESTA, G.; CILLIERS, P.. From representation to emergence: Complexity's challenge to the epistemology of schooling. Educational philosophy and theory, London, v. 40, n. 1, p. 213-227, 2008.

PALMIERI, M. L. B. Os projetos de Educação Ambiental desenvolvidos nas escolas brasileiras: análise de dissertações e teses. 2011. 189 f. Dissertação (Mestrado em Educação) - Universidade Estadual Paulista, Rio Claro, 2011.

PRIGOGINE, I. O fim das certezas: tempo, caos e as leis da natureza. São Paulo: Ed. Unesp, 2011.

SILVA, L. F. A temática ambiental, o processo educativo e os temas controversos: implicações teóricas e práticas para o ensino de física. 2007. 211 f. Tese (Doutorado em Educação) - Universidade Estadual Paulista, Araraquara, 2007.

SILVA, R. L. F.; FERNANDES, J. A. B. Language and discourse in environmental education research in Brazil: a study of the EArte platform. Pesquisa em Educação Ambiental, Rio Claro, v. 13, edição especial, p. 128-141, 2018.

SOUZA, H. A. L. A "Ética Ambiental” na produção teórica (Dissertações e Teses) em Educação Ambiental no Brasil. 2012. 200 f. Dissertação (Mestrado em Educação) - Universidade Estadual Paulista Rio Claro, 2012.

SOUZA, D. C. Cartografia da educação ambiental nas pós-graduações Stricto Sensu brasileiras (2003-2007): ênfase na pesquisa das áreas de Educação e de Ensino de Ciências sobre formação de professores. Dissertação (Mestrado em Ensino de Ciências e Educação Matemática) - Centro de Ciências Exatas, Universidade Estadual de Londrina, Londrina, 2010.

STRIEDER, R. B. et al. Educação CTS e Educação Ambiental: ações na formação de professores. Alexandria: Revista de Educação em Ciência e Tecnologia, Florianópolis, v. 9, n. 1, p. 57- 81, 2016.

SZEKELY, E.; MASON, M.. Complexity theory, the capability approach, and the sustainability of development initiatives in education. Journal of Education Policy, London, v. 34, n. 5, p. 669-685, 2018.

TAVARES, C. M. S.; BRANDÃO, C. M. M.; SCHMIDT, E. B. Estética e Educação Ambiental no paradigma da complexidade. Pesquisa em Educação Ambiental, Rio Claro, v. 4, n. 1, p. 177-193, 2009.

VASCONCELLOS, M. M. N.; GUIMARÃES, M. Educação ambiental e educação em ciências: um esforço de aproximação em um museu de ciências-MAST. Ambiente \& Educação, Rio Grande, v. 11, n. 1, p. 165-174, 2009.

WATANABE-CARAMELLO, G.; KAWAMURA, M. R. D. Uma educação na perspectiva ambiental crítica, complexa e reflexiva. Revista Brasileira de Pesquisa em Educação em Ciências, Belo

Horizonte, v. 14, [s.n], p. 255-264, 2014. 